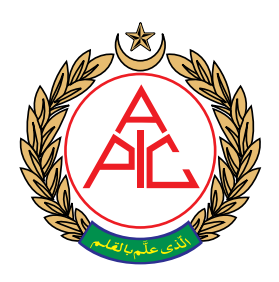

\title{
A comparative study of the effect of intrathecal tramadol and buprenorphine used as adjuvants to hyperbaric bupivacaine for postoperative analgesia in infraumbilical surgeries
}

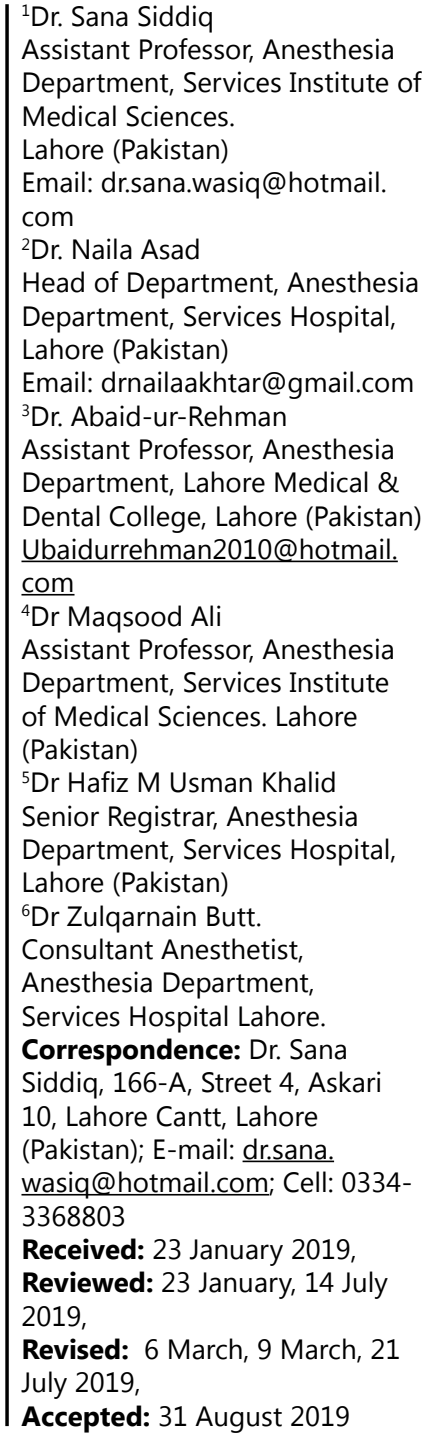

\author{
Sana Siddiq ${ }^{1}$, Naila Asad ${ }^{2}$, Abaid-ur-Rehman ${ }^{3}$, Maqsood $\mathrm{Ali}^{4}$, \\ Hafiz M Usman Khalid ${ }^{5}$, Zulqarnain Butt ${ }^{6}$
}

\begin{abstract}
Background \& Objective: The augmentation of local anesthetics with various adjuvants to enhance the quality and efficacy of subarachnoid block is clinically in practice since long. Comparative studies on effects of adding intrathecal tramadol and buprenorphine has never been studied before. Both drygs are esily available in our country. So, we conducted this study to evaluate and compare the characteristics of subarachnoid blockade, duration of postoperative analgesia, dose of recue analgesic postoperatively, and adverse effects of intrathecal buprenorphine $(50 \mu \mathrm{g})$ and intrathecal tramadol (30 $\mathrm{mg}$ ) as adjuvants to $0.5 \%$ hyperbaric bupivacaine for lower abdominal surgeries
\end{abstract}

Methodology: This prospective randomized, single blind controlled trial was carried out at_Services Hospital Lahore, from January to July 2018. 110 American society of Anesthesiologist I - II male patients, 35 to $45 \mathrm{y}$ of age undergoing subarachnoid block for infra-umbilical surgery were randomized into two groups. Group $T(n=55)$ patients received $10 \mathrm{mg}$ of $0.5 \%$ bupivacaine and $30 \mathrm{mg}$ of tramadol intrathecally, while group $B$ $(n=55)$ received $10 \mathrm{mg} 0.5 \%$ bupivacaine with $50 \mu \mathrm{g}$ of buprenorphine. Sensory testing was done by pin prick method using $25 \mathrm{G}$ blunt needle and time taken to reach T10 level noted. Motor block was assessed using Modified Bromage Scale. The time taken to reach modified Bromage 3 was recorded. Side effects and postoperative analgesia noted for $24 \mathrm{~h}$ by VAS score every 20 min for first $2 \mathrm{~h}$ in PACU and then 4 hourly for 24 $\mathrm{h}$ in the ward. Patients with inadequate block were converted into general anesthesia and were excluded from the study. Time to first rescue analgesia, and total analgesic required in $24 \mathrm{~h}$ were compared in two groups.

Results: Mean VAS scores were less in Group T as compared to Group B. Significant difference was seen among groups at $45 \mathrm{~min}(p=0.04), 60 \mathrm{~min}(p=0.02), 75 \mathrm{~min}(p$ $=0.03), 90 \mathrm{~min}(p=0.01), 120 \mathrm{~min}(p=0.00), 4 \mathrm{~h}(p=0.007), 8 \mathrm{~h}(\mathrm{p}=0.01), 12 \mathrm{~h}(\mathrm{p}$ $=0.01), 16 \mathrm{~h}(p=0.00)$. After $24 \mathrm{~h}$ no significant difference was seen in both groups. Mean onset time for sensory block was earlier in Group B (2.4 min) compared to Group $\mathrm{T}(2.7 \mathrm{~min})(\mathrm{p}=0.001)$. Mean onset time for motor block was earlier in Group B (4.8 min) as compared to Group T $(5.5 \mathrm{~min})(\mathrm{p}=0.00)$. No significant difference was seen among groups in side effects ( $p>0.05)$. Mean time for rescue analgesia in Group B was earlier $(4.51 \pm 2.8 \mathrm{~h}$.) as compared to Group T $(4.94 \pm 4.1 \mathrm{~h})$. Total dose of analgesic given in 24 $\mathrm{h}$ was significantly less in group $\mathrm{T}$. $(\mathrm{p}=0.004)$ The mean dose given in Group B (1.24 \pm $0.96 \mathrm{mg} / \mathrm{kg}$ ) was greater than Group T $(0.76 \pm 0.71 \mathrm{mg} / \mathrm{kg})$

Conclusion: We conclude that both tramadol and buprenorphine, prolong the duration of postop analgesia without adding any adverse effects, but duration with tramadol is longer; it significantly reduces VAS and the dose of analgesic requirement in $24 \mathrm{~h}$ postoperatively. 
tramadol vs. buprenorphine as adjuvants to intrathecal bupivacaine

Key words: Tramadol; Buprenorphine; Bupivacaine; Post-operative analgesia; Anesthesia, Spinal.

IRB letter No. IRB/2018/427/SIMS

Citation: Siddiq S, Asad N, Rehman AU, Ali M, Khalid HMU, Butt Z. A comparative study of the effect of intrathecal tramadol and buprenorphine used as adjuvants to hyperbaric bupivacaine for postoperative analgesia in infraumbilical surgeries. Anesth pain \& intensiv care 2019;23(3):263-267

\section{INTRODUCTION}

Subarachnoid block is one of the most widely practiced and effective regional approach for elective and emergency cesarean sections, lower abdominal surgeries, lower limb orthopedic and urological procedures. ${ }^{1}$ it has earned its high popularity due to low cost, awake patient, prompt onset, and rapid recovery and no need of airway manipulation. ${ }^{2}$

The duration of postoperative analgesia can be prolonged by adding a small dose of opioid as adjunct with local anesthetic solution in intrathecal space. Intrathecal opiates function synergistically with local anesthetics and augment their sensory block without impacting the sympathetic activity. ${ }^{3}$ Opioids act by activation of opioid receptors in the dorsal gray matter of spinal cord, which modifies the function of afferent pain fibers. ${ }^{4}$ The use of opioids through other routes has been associated with high frequency of undesirable side effects, including respiratory depression, sedation, hypotension, bradycardia, nausea, and vomiting. ${ }^{5}$ American Society of Anesthesiologists (ASA) recommends neuraxial opioids over parenteral opioids for postoperative analgesia after neuraxial blocks. ${ }^{6}$

Buprenorphine is a long-acting, lipid soluble, mixed agonist-antagonist opioid. ${ }^{3}$ It is known to increase duration of analgesia at least by $12-15 \mathrm{~h}$, without causing any significant fall in BP or pulse rate when used intrathecally. ${ }^{7}$

Tramadol is not a centrally acting opioid analgesic and it has very less respiratory depressant effecr due to its 6000 -fold less affinity for $\mu$-receptors in contrast to morphine. It also discourages serotonin and norepinephrine reuptake in the spinal cord and has no revealed neural toxicity. ${ }^{8}$ It's low cost, easy availability and its ability to extend the span of sensory block, motor block, and postoperative analgesia make it an attractive adjuvant to spinal anesthesia. ${ }^{9}$

Not much published work is available comparing analgesic properties of intrathecal buprenorphine to other narcotics such as tramadol. Hence, we conducted this prospective, randomized control trial to evaluate and compare the characteristics of subarachnoid block, postoperative analgesia and sideeffects with the addition of buprenorphine $(50 \mu \mathrm{g})$ or tramadol $(30 \mathrm{mg})$ to $0.5 \%$ hyperbaric bupivacaine in infra-umbilical surgeries.

\section{METHODOLOGY}

After approval from institutional ethical review committee, this prospective, randomized, single blind control study was conducted at Department of Anesthesiology, Services Hospital Lahore. Sample size was calculated using WHO statistical software SSIZE, based upon hypothesis test for difference of two means. At significance level of alpha $5 \%$ and power of study $80 \%$, estimated sample size was 55 for each group. Sampling technique used was nonprobability convenience.

Patients aged 18-60 y of either sex, belonging to ASA Physical Status I and II, scheduled for elective hernia repair, requiring sub arachnoid block were included in the study. Patients who were taking $\alpha 2$-adrenergic agonist or antagonist therapy, patients who were having labile hypertension, uncontrolled cardiac disease, heart block/dysrhythmia, autoimmune disorders, communication difficulties, e.g. mental retardation or deafness and allergy to the drug or local anesthetics were excluded from study. The enrolled patients were randomized by computer generated random number sequence and blind envelop technique into two groups; Group B and Group T, each comprising of 55 patients. Group B received $2 \mathrm{ml}$ of $0.5 \%$ of hyperbaric bupivacaine and $1 \mathrm{ml}$ of $50 \mu \mathrm{g}$ buprenorphine $(0.3 \mathrm{mg}$ diluted in $6 \mathrm{ml}$ normal saline). Group $\mathrm{T}$ received $2 \mathrm{ml}$ of $0.5 \%$ hyperbaric bupivacaine and $1 \mathrm{ml}$ of $30 \mathrm{mg}$ tramadol (100 $\mathrm{mg}$ diluted in $3.2 \mathrm{ml}$ normal saline). Total drug volume used was $3 \mathrm{ml}$ in both groups.

On arrival to the operating room, IV access was secured and patients preloaded with $10 \mathrm{ml} / \mathrm{kg}$ of crystalloid solution over $15 \mathrm{~min}$. The baseline systolic and diastolic blood pressures, heart rate and oxygen saturation were recorded.

After all aseptic measures subarachnoid block was performed and the study drug was injected along with bupivacaine at L3-L4 interspace, over 10-15 sec. The time of injection completion was considered zero time for the study and all measurements were recorded from this point. 
original article

Following the block, patients were made to lie supine. Time taken to reach sensory block till t10 and motor block till modified bromage scale 3 was recorded. Sensory testing was done by pin prick method using 25G hypodermic blunt needle and time taken to reach T10 level noted down. Patients did not receive any additional analgesic in intraoperative period while anxious patients received intravenous midazolam $1 \mathrm{mg}$. The incidence of any adverse effects such as hypotension, bradycardia, shivering, nausea, vomiting, pruritus, respiratory depression or ECG changes were noted. Hypotension was defined as a fall in systolic blood pressure by 30\% from baseline. Bradycardia was defined as a heart rate less than 50 beats per min. From zero min till demand of first rescue analgesia by the patient was defined as postop analgesia. Hypotension and bradycardia was treated with fluid bolus, phenylephrine $50 \mu \mathrm{g}$ aliquots and atropine $0.6 \mathrm{mg}$ respectively. Post-operatively the hemodynamic variables and oxygen saturation were recorded in the PACU until complete recovery of the patients from anesthesia.

Postoperatively, pain was assessed using VAS every 15 min during first $2 \mathrm{~h}$ and then regularly at an interval of $4 \mathrm{~h}$ till the next 24 $\mathrm{h}$ in the ward. Whenever VAS score reached $>4$, rescue analgesia was given in the form of inj tramadol $1 \mathrm{mg} / \mathrm{kg}$ IV. Time to the first dose of tramadol and the total dose required during first $24 \mathrm{~h}$ was recorded.

After completion of the study, the results were compiled and statistically analyzed using Chi-square test for categorical data; the intergroup comparison was analyzed using independent student's T-test. IBM SPSS Statistics 25 was used for statistical analysis. $\mathrm{P}<0.05$ was considered as significant.

\section{RESULTS}

All patients in Group B and T were male, ASA I and II, and all underwent inguinal hernia repair. Mean age in Group B and T was $40.35 \pm 13.12$ y and $40.16 \pm 11.56$ $\mathrm{y}$ respectively. The characteristics of subarachnoid block and observed side-effects between both groups are shown in Table 1 and Table 2 respectively.

Table 3 shows duration of postop analgesia, total dose of rescue analgesia used within $24 \mathrm{~h}$. Total dose used in $24 \mathrm{~h}$ is significantly reduced in Group T, but the duration of postop analgesia is not statistically significant among both groups.

VAS scores for $24 \mathrm{~h}$ postoperative period

of both groups are shown in Table 3. VAS scores were significantly low in Group $\mathrm{T}$ at 1.5, $2,4,8,12$, and $16 \mathrm{~h}$. At $24 \mathrm{~h}$ it was comparable in both groups.

8 patients out of 55 in tramadol group and 4 patients out of 55 in buprenorphine group experienced hypotension; whereas, 10 patients in tramadol group and 8 patients in buprenorphine group complained of nausea. Incidence of shivering was more in buprenorphine groups. No adverse effects like pruritus, ECG changes, bradycardia or respiratory depression were encountered in either of the groups.

\section{DISCUSSION}

Tramadol and buprenorphine both have proven to be effective drugs for postop analgesia. In Pakistan currently only these two drugs are easily available for use as adjuvant in intrathecal space. However, no randomized control trial to compare their effectiveness in prolonging the duration of postopanalgesia, block characteristics and adverse effects has ever been conducted. 
A study conducted in India in 2017 showed onset of sensory block to be $1.91 \pm 0.438 \mathrm{~min}$ and onset of motor block to be $2.4 \pm 0.572 \mathrm{~min}$, when 20 $\mathrm{mg}$ tramadol was used with $15 \mathrm{mg}$ of bupivacaine intrathecally. The results of demand for first rescue analgesia in this study are comparable to our results i.e. $324 \pm 5.79 \mathrm{sec}$, but the onset of sensory and motor block was faster, probably due to higher dose of bupivacaine used. ${ }^{8}$

Jamadar et al. found that duration of postop analgesia was prolonged to $(317.14 \pm 6.54 \mathrm{~min})$ when $20 \mathrm{mg}$ tramadol was added to $9 \mathrm{mg}$ bupivacaine, which is consistent with our results. ${ }^{11}$

A study by Chakrbarty et al. investigated tramadol, and found duration of effective analgesia to be $380 \pm 11.82 \mathrm{~min}$. He also studied VAS score in postop period. Similar to our findings, the VAS scores were remarkably reduced i.e. less than $4,6 \mathrm{~h}$ postoperatively. ${ }^{12}$

A study done in Karnatka in 2015 showed prolongation of effective postop analgesia till $232.18 \pm 80.85 \mathrm{~min}$, and time to achieve highest sensory block of $4.80 \pm$ $1.09 \mathrm{~min}$, when $10 \mathrm{mg}$ of tramadol was used as an adjuvant with bupivacaine. This difference in results is most probably due to lower dose of tramadol being used. ${ }^{13}$

Another study conducted in India in 2014 studied effects of adding $60 \mu \mathrm{g}$ of buprenorphine with 15 $\mathrm{mg}$ of bupivacaine. Duration of postop analgesia was similar to our observation of $289.66 \pm 64.94$ min. ${ }^{10}$ The variation is seen in onset of motor blockage that is faster probably due to higher dose of both drugs used. Study done by Anoop et al. in 2015 studied prolongation of postop analgesia with buprenorphine for $283.20 \pm 51.84 \mathrm{sec}^{14}$

Sandhya Gujar et al. found prolongation of postop analgesia up till $11.65 \mathrm{~h}$ when he added $150 \mu \mathrm{g}$ of buprenorphine with $3.5 \mathrm{ml}$ of $0.5 \%$ bupivacaine. It is significantly greater than our finding. This might be due to three times the dose of buprenorphine used instead of $50 \mu \mathrm{g}$ used in our study.

Kamal Sonya and Davies studied effect of adding 75 $\mu \mathrm{g}$ of buprenorphine in $1.8 \mathrm{ml}$ of $0.5 \%$ bupivacaine. Duration of postop analgesia was prolonged to $317 \pm$ $55 \mathrm{~min}$ and maximum sensory level was achieved in $4.56 \pm 1.21$ min. $^{15}$

A study done in 2017 by Navdeep Kaur et al. added 60 $\mu \mathrm{g}$ of buprenorphine with $1.8 \mathrm{ml}$ of $0.5 \%$ hyperbaric bupivacaine. These results are in contradiction to our study, duration of postop analgesia was prolonged to $589 \pm 158.3 \mathrm{~min}^{16}$

In our study VAS never rose above 2.95 and 2.20 in Group B and T respectively as 14 (25\%) patients in Group B and 22 patients (40\%) in Group T did not complain of pain and didn't receive any rescue analgesic, and there VAS did not rose above 2 in postoperative period. Because of those patients the overall VAS score of both groups is reduced, as VAS is calculated as mean of all patients of both groups.

Tramadol and buprenorphine both are semisynthetic opioids and are used as adjuvants for spinal anesthesia to prolong period of effective postop analgesia. Buprenorphine is 20 to 30 -fold more potent than morphine, due to its high lipid solubility. ${ }^{17}$ It has significantly strong binding at $\mathrm{mu}$ receptors and can nearly maximally occupy them, and due to its slower dissociation rate of 166 mins it cannot be easily displaced by full opioid agonists. ${ }^{18}$ Tramadol, a centrally acting anodyne comprises of two enantiomers, both of which offer analgesia via different modes. (+)-tramadol and the metabolite (+)-O-desmethyl-tramadol (M1) are agonists of the mu opioid receptor. (+)-tramadol inhibits serotonin reuptake and (-)-tramadol inhibits norepinephrine reuptake, enhancing inhibitory effects on pain transmission in the spinal cord. ${ }^{19}$ This dual mechanism of action might explain the longer duration of postoperative analgesia and better VAS scoring in tramadol group in our study.

\section{LIMITATIONS}

Some limitations of our study were that we did not compare the changes in blood pressure among the two groups after intrathecal administration. Also, the mean age range was $42-44$ years and older patients were not assessed. Future studies can be done to find any changes in hemodynamics and effects in elderly patients too.

\section{CONCLUSION}

Tramadol and buprenorphine are found to be effective adjuvants for prolonging postoperative analgesia, when added to intrathecal bupivacaline, but tramadol was associated with significantly reduced VAS scoring, prolonged duration of postop analgesia and reduced total dose of parenteral analgesics used in 24 $\mathrm{h}$ postoperatively without any significant difference in side effects.

Conflict of interest: None declared by the authors

Authors' Contribution

SS: concept, conduction, manuscript writing

NA: manuscript editing, review, data analysis

$A R$ : reference writing, manuscript editing

MA, HMU, ZB: Data collection 


\section{REFERENCES}

1. Negi AS, Gupta M, Singh A. Comparison effects of intrathecal buprenorphine and clonidine as an adjuvant to hyperbaric bupivacaine on sub-arachanoid block characteristics. JORAPAIN. 2015;1(2):67-72. DOI: 10.5005/ ip-journals-10046-0014

2. Zahid F, Tarar HM, Tariq M, Nazir H, Zafar I, Munir S. Intrathecal tramadol as an adjuvant in sub-arachanoid block to prolong the duration of analgesia. Pak Armed Forces Med J. 2017;67(4):534-9. [Free Full Text]

3. Rabiee SM, Alijanpour A, Jabbari A, Rostami S. Benefits of using intrathecal buprenorphine. Caspian J Intern Med. 2014;5(3):143-7. [PubMed]

4. Verma D, Naithani U, Jain DC, Singh A. Postoperative analgesic efficacy of intrathecal tramadol versus nalbuphine added to bupivacaine in spinal anaesthesia for lower limb orthopaedic surgery. J Evolution Med Dental Sci. 2013;2(33):6196-206. DOI: 10.14260/jemds/1118

5. Masamaddi GS, Narendra MC. Hemodynamic and sedative effects of intrathecal tramadol with bupivacaine and bupivacaine alone in patients undergoing elective lower abdominal surgery: a comparative study. Int J Sci Study. 2016;4(9):154-7. DOI: $\underline{10.17354 /}$ ijss/2016/635

6. Ravindran R, Sajjid B, Thekkethil K, Susheela I. Intrathecal hyperbaric bupivacaine with varying doses of buprenorphine for postoperative analgesia after cesarean section: a comparative study. Anesth Essays Res. 2017 0ctDec;11(4):952-7. [PubMed] DOl: 10.4103/aer.AER_82_17

7. Gujar S, Jagtap P, Swapnil, Tejas, Kruti. Adjuvants to spinal anaesthesia - what is better, comparison between intrathecal clonidine with intrathecal buprenorphine. Sch J App Med Sci. 2014; 2(4B):1274-7. [Free Full Text]

8. Meena S, Agarwal R, Sunar RC. A comparative study effect of intrathecal tramadol $(20 \mathrm{mg})$ use as adjuvant with hyperbaric bupivacaine $(15 \mathrm{mg})$ and hyperbaric bupivacaine for postoperative analgesia in infraumbical surgeries. Int J Adv Res. 2017;5(7):2671-5. DOI: $10.21474 /$ IJAR01/5009

9. Gupta M, Gupta P. Intrathecal tramadol for prevention of postanesthesia shivering after subarachnoid block: a prospective randomized placebo-controlled comparison of two different doses (10 and $20 \mathrm{mg}$ ). Anesth Essays Res. 2018 Apr-Jun;12(2):495-500. [PubMed] DOI: 10.4103/aer. AER $75 \quad 18$

10. Gupta M, S. Shailaja, Hegde KS. Comparison of intrathecal dexmedetomidine with buprenorphine as adjuvant to bupivacaine in spinal anaesthesia. J Clin Diagn Res. 2014 Feb;8(2):114-7. [PubMed] DOl: 10.7860/JCDR/2014/7883.4023

11. Jamadar NP, Ganesh K,Sandeep G, Vikram S, Lanjewar. Comparative study of intrathecal administration of bupivacaine - ketamine with bupivacaine -tramadol in patients for non PIH caesarean section. Indian J Basic Applied Med Res. 2013;3(1):184-92. [Free Full Text]

12. Chakraborty S, chajrabarti J, Bhattacharya D. Intrathecal tramadol added to bupivacaine as spinal anesthetic increases analgesic effect of the spinal blockade after major gynecological surgeries. Indian J Pharmacol. 2008 Aug;40(4):180-2. [PubMed] DOl: $\underline{10.4103 / 0253-7613.43166}$

13. Parasad RB, Joel CJ, Zachariah VK. Effectiveness of addition of intrathecal tramadol with hyperbaric bupivacaine in prevention of shivering in partu- rients undergoing cesarean section under spinal anesthesia: A randomized placebo-controlled study. Karnatka Anaesth J. 2015;1(3):123-7. DOI: $\underline{10.4103 / 2394-6954.173536}$

14. Negi AS, Gupta M, Singh A. Comparison of effect of intrathecal buprenorphine vs clonidine as an adjuvant to hyperbaric bupivacaine on subarachnoid block characteristics. J Recent Advances Pain. 2015;1(2):67-72. DOI: 10.5005/ip-journals-10046-0014

15. Sonya K, Davies CV. A prospective randomised double blind study of the comparison of two opioids- fentan$\mathrm{yl}$ and buprenorphine - as adjuvant to spinal bupivacaine in caesarean sections. Int J Clin Trials. 2017 Feb;4(1):45-8. DOI: 10.18203/2349$\underline{3259 . i j c t 20170308}$

16. Kaur N, Goneppanavar U, Venkateswaran R, lyer SS. Comparative effects of buprenorphine and dexmedetomidine as adjuvants to bupivacaine spinal anaesthesia in elderly male patients undergoing transurethral resection of prostrate: a randomized prospective study. Anesth Essays Res. 2017 Oct-Dec;11(4):886-91. [PubMed] DOI: 10.4103/aer. AER $163 \_17$

17. Castro JA, Torress OC, Navaroo $P G$. Role of buprenorphine in acute postoperative pain. Science direct. July-Sep 2016;79(3):174-80. DOI: 10.1016/i.hgmx.2016.05.008

18. Bettinger JJ, Fudin J, Argoff CE. Buprenorphine and surgery: what's the protocol?" practicle pain management. 2017;2(1):73-80. [Free Full $\underline{\text { Text] }}$

19. Grond S, Sablotzki A. Clinical pharmacology of tramadol. Clin Pharmacokinet. 2004;43(13):879-923. [PubMed] DOI: 10.2165/00003088200443130-00004 